\title{
En torno al entrenamiento deportivo
}

flexiones y re-flexiones

ALFONSO MARTIN*

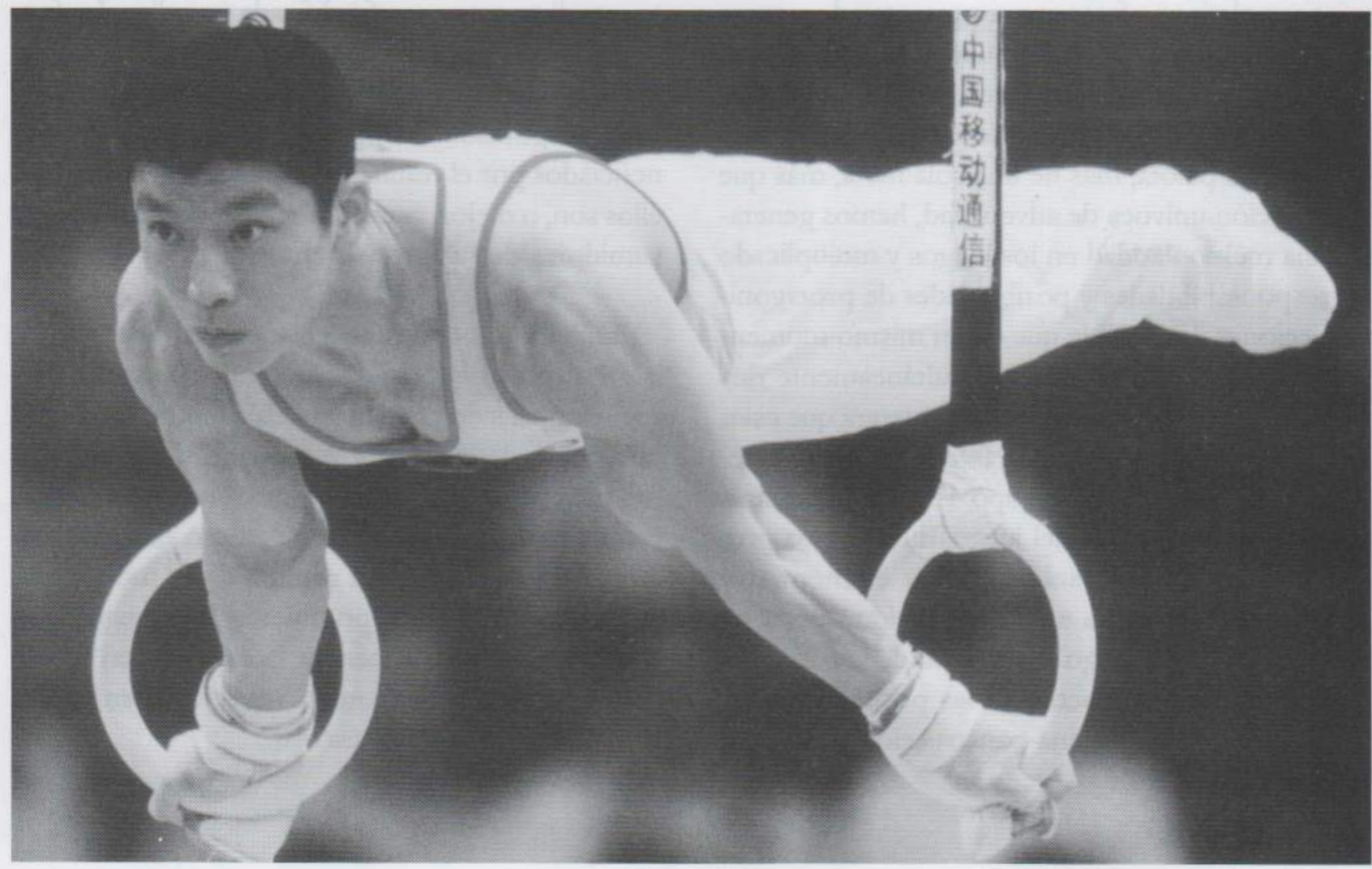

Revista International Gymnast. USA. December, 1994

\section{Resumen}

\section{9}

n la teoría del entrenamiento ha habido una marcada preferencia hacia el estudio de los aspectos fisiológicos del esfuerzo, al igual que hacia los resultados, lo que ha conducido a la cosificación del sujeto deportista. La intención del articulo es aportar algunas reflexiones que buscan una visión mas compleja del fenómeno deportivo.

Fecha de recepción: septiembre 4 de 2003 - Fecha de aceptación: octubre 21 de 2003

* Profesor Facultad de Educación Física. Universidad Pedagógica Nacional. 
Palabras clave: teoría, entrenamiento, deporte, flexiones, re-flexiones, insular, peninsular, pedagógico.

\section{Abstract}

In the theory of the training there has been a marked preference toward the study of the physiologic aspects of the effort, the same as toward the results, what has led to convert the sportsman in a thing. The intention of the text is to contribute some reflections that they look for a vision more complex of the sport phenomenon.

No es sólo teoría lo relativo a la ciencia o la técnica. Mucho se ha escrito acerca del entrenamiento deportivo, su manifestación última, el deporte, es una de las actividades privilegiadas por el mundo moderno; sus gestas, sus ídolos, son tanto o más resonantes que un presidente, o un científico. Sus actores merecen grandes titulares y espacios en los medios de difusión, su realización paraliza un país y ocupa un puesto primordial en la economía mundial. Algunos gobiernos destinan generosas sumas de dinero en su desarrollo para demostrar poderío. En Colombia, particularmente, cada cuatro años se expone un nuevo plan, esta vez si en serio, para ocupar el puesto que "nos merecemos".

Se afirma, además, que su práctica forma y desarrolla, de manera integral, a todos los practicantes; es de suponer que de manera espontánea y silvestre, porque si bien es cierto que tal desarrollo siempre se incluye en los objetivos, curiosamente nunca se hace lo mismo en el proceso, ni se comprueba en las evaluaciones. En ellas solo se miden los resultados obtenidos, las marcas, los goles, los puntos, el lugar ocupado etc, jamás los valores desarrollados, el modelo de ciudadano formado, o el beneficio social obtenido. Es más, se gana solo si se ocupa el primer puesto, cualquier otro lugar es pérdida.

Trasegando por el deporte, es posible observar generaciones completas de deportistas en modalidades diferentes, varios de las cuales posteriormente a su práctica se encuentran con problemas de salud, económicos, sociales; incapaces de transferir la disciplina, el tesón, el sistema, la organización, supuesta herencia de la práctica deportiva, a las actividades de su vida cotidiana.
Tal vez todo esto ocurra, en razón a que del entrenamiento deportivo se ha hecho una actividad insular, como se refleja en la mayoría de textos a nuestro alcance, alejados por completo de las diversas esferas de la actividad humana. Lo hemos vuelto insular porque ha sido encerrado dentro de fronteras monolíticas y estrictas.

Se ha venido viendo al deportista como un elemento de manifestación muscular: de resistencia, velocidad o fuerza; la clásica visión osteomuscular, cardiovascular y algunas veces neurofisiológica. El deporte es simultáneamente biológico, cerebral, espiritual, cultural, social, histórico y económico; su relación es con el hombre, la sociedad, la vida y el mundo, por tanto, de esa manera debe ser tratado. Para conocer al entrenamiento deportivo debemos unirlo al continente de que forma parte, convertirlo en peninsular.

Se ha dedicado demasiado y casi exclusivo tiempo a las flexiones y sus consiguientes extensiones, $y$ como sabemos, ello nos conduce a una hipertrofia muscular, proceso para el cual somos todos expertos. No obstante, jamás será tarde para las reflexiones, que nos pueden llevar a una extensión ya no muscular, sino del sentido y el significado del fenómeno deportivo, que permita una mejora del órgano responsable de esa tarea y sospechosamente olvidado en la mayoría de textos propios de la especialidad: el cerebro. Es bastante probable que nuestro deficiente desarrollo en deporte se deba más a falta de ideas que de músculo.

Por supuesto, no se puede caer en el exceso holístico de ver el todo, pero tampoco de dedicarnos sólo a una parte. Nuestro trabajo es navegar 
continuamente entre los dos extremos y acercarnos así, a los principios básicos de calidad que deberían guiar el entrenamiento deportivo.

Tal como lo plantea Molnar (2001), lo esencial para el estudio del entrenamiento deportivo es el concepto de sinergia: en el que el todo es más que la suma de las partes. Es decir que el efecto debido a la acción de dos o más causas es superior a la suma de los efectos individuales. "No existe un componente del entrenamiento que tomado aisladamente, sea más importante que los otros", Molnar (2001).

En occidente somos herederos de una forma de conocimiento, la vía de la separación, es nuestra experiencia histórica. De esa forma nos hemos alejado de la totalidad. Somos objetivos, con una lógica aplastante, demoledora, triunfante, cerrada sobre sí misma, poseedora de la ultima palabra, es "la teoría sabelotodo que detesta la realidad, que la contradice y detesta el conocimiento que la contesta", Morin (1984: 69).

Esta lógica ha derivado en una especialización que produce progreso, pero también regresión, "en el sentido que los conocimientos fragmentarios y no comunicantes que progresan significan al mismo tiempo el progreso de un conocimiento mutilado; y un conocimiento mutilado siempre conduce a una práctica mutilante", Morin (1984: 7).

En el entrenamiento vivimos buscando innovaciones; pese a ello, los principios básicos no han cambiado en decenios. Lo que sí tenemos son nuevas tecnologías que nos permiten ver los mismos conceptos a la luz de una mirada contemporánea. Por desgracia, seguimos convencidos de que la tecnología nos dará la fórmula mágica para obtener la $\tan$ ansiada figuración. Por fortuna para nosotros, esa magia no existe. Sin disciplina, autonomía, manejo de principios, lectura del entorno y una auténtica aprehensión del conocimiento, figurar entre los primeros, será producto del azar. El éxito es el resultado, la consecuencia, y nosotros, lo hemos convertido en un fin.
En Colombia, manejamos metodología moderna, tecnología de punta y marcas de hace dos décadas. Estos resultados deberían inducir a hacernos algunas preguntas: ¿será que lo social, lo económi$\mathrm{co}$, lo cultural, lo político tiene algo que ver...?, ¿podremos aislarnos del entorno, o éste media, profundamente, en los resultados?, ¿si es así, no deberíamos utilizar el deporte para modificarlo de manera favorable y después preocuparnos por las marcas y las medallas?, o ¿tal vez asumimos conceptualmente el entrenamiento deportivo de manera muy superficial?

En nuestro medio, aún creemos que entrenando más, mejoraremos de inmediato los resultados, ¿cuándo nos preocupamos por la eficiencia, la eficacia y más importante, la calidad?, sabemos como entrena la elite mundial, pero no nos damos cuenta que nuestro ambiente, comparativamente, es totalmente adverso para su práctica.

Sostenemos que el entrenamiento deportivo es un proceso pedagógico, pero sólo nos interesamos por su didáctica; tomamos al deportista como un objeto, lo hemos cosificado. Estamos en mora de establecer la relación sujeto-sujeto y así generar un real tejido social con sus intra e ínter subjetividades.

Ya que hablamos de un proceso pedagógico, es conveniente aclarar que lo pedagógico exige un ideal de ciudadano y sociedad; un modelo con la suficiente y necesaria argumentación que lo justifique, cuya consecución, además, debe ser incluida en la evaluación; esto exige el desarrollo de valores y actitudes coherentes con el fin propuesto. No sobra reiterar que el ser "deportista" se manifiesta en un contexto histórico, económico, político y social. Este determina y afecta de manera sustancial su rendimiento.

Es importante considerar que nuestra realidad es significativamente diferente a la de países desarrollados. Los niveles de pobreza, violencia e injusticia en nuestro país, no permiten hacer una copia fiel de otros con distintas realidades $\sin$ antes hacer un inventario acerca de nuestra propia situación. 
Esta decisión de imitar, sólo nos ha llevado por el camino del continuo fracaso.

Es vital utilizar la ciencia para ver al deportista como un ser social al cual se le debe capacitar para tomar sus propias decisiones y que por medio del deporte se transforme en un ser analítico y autónomo, capaz de colaborar para construir un mundo mejor.

Después de esto y a la luz de las reflexiones hechas puedo atreverme a intentar un definición de entrenamiento deportivo.

Entrenamiento deportivo: proceso pedagógico, sistemático, perdurable, dirigido a desarrollar un ser íntegro, posibilitado para lograr un máximo rendimiento y para transferir todas las experiencias del deporte a las demás actividades de la vida.

Pedagógico: proceso intencional que involucra la transformación de ideales, valores y actitudes, de acuerdo con un modelo de hombre y sociedad, proyecto que deberá ser suficiente y necesariamente argumentado y confrontado con los resultados obtenidos.

Sistemático: porque debe obedecer a un sistema; es decir, a un conjunto de reglas y principios racionalmente enlazados, con objetivos y controles concretos.

Perdurable: si hay algo arraigado en nuestro sistema social, deportivo, económico, es el inmediatismo, todo lo queremos rápido y fácil. $\mathrm{La}$ disciplina no es precisamente nuestra característica, estudiamos las leyes de la adaptación y luego las violamos en la práctica, como se dice popularmente: "lo que sube como palma, cae como coco" una frase que deberíamos recordar a menudo. La variable mas altamente relacionada con la solidez y perdurabilidad del aprendizaje es el tiempo empleado en su adquisición. El deporte debe enseñar una actitud hacia la vida, de por vida.

Máximo rendimiento: máximo posible sin producir daño, permitiendo mejorar la salud y potenciar al individuo para su vida cotidiana, para lo cual se debe constantemente leer el contexto.

Transferencia a la vida: todos los valores y características propios del deporte como el orden, la disciplina, la persistencia, la paciencia, el respeto a las normas, al competidor, etc., deben ser transferibles a la vida cotidiana; ese es el auténtico reto de aquel que pretenda construir un modelo de hombre y sociedad, utilizando el deporte como medio especialmente en una sociedad como la nuestra.

Pueden parecer preguntas de perogrullo pero, ¿si el niño de hoy es el ciudadano del mañana y aprende desde joven que para ganar siempre hay que derrotar a otro, cueste lo que cueste, que podemos esperar luego? ¿Cómo le exigimos creatividad si lo hacemos seguir instrucciones durante años? ¿Cómo le exigimos que piense, si hay un predominio de las flexiones sobre las reflexiones? ¿Cómo a partir de una actividad dogmática pretendemos formar un hombre libre?, o con todos los problemas que aquejan nuestro país, ¿̇está bien que se destinen ingentes sumas de dinero para desarrollar proyectos, sueños, ilusiones de preseas doradas, en una actividad que debería ser un medio y no un fin?

Para concluir, estas son preguntas que normalmente no estamos dispuestos a discutir, porque son muchos los que viven del deporte. No por y para él.

\section{Bibliografía}

MORIN, Edgar. (1984). Ciencia con conciencia. Barcelona. Anthropos.
MOLNAR, Gabriel. (2001). "Un concepto de entrenamiento". Disponible en www.sobrentrenamiento.com. 